\title{
TEMPORARY HEMIPLEGIA FOLLOWING SYMPTOMATIC CONVULSIONS
}

\author{
BY \\ ELI DAVIS, M.Sc., M.D., M.R.C.P. \\ (From St. Stephen's Hospital, London County Council)
}

The possibility that temporary hemiplegia may follow symptomatic convulsions receives scant notice-and sometimes no mention-even in the larger works on paediatrics. Two recent personal cases are therefore being recorded.

Case 1, P .B., a well-nourished female child, eleven months old, hitherto healthy, who had been weaned at nine months, was admitted at 7 p.m. on September 16, 1937. She had become flushed and ill six hours previously. Just before admission she became unconscious, and jerking movements of her left side were seen. On admission she was cyanosed, in coma, with clonic movements of the left arm and leg, and spasticity of the left side. Her temperature was $99 \cdot 2^{\circ} \mathrm{F}$., pulse rate 160 , and respirations 38 per minute. Nothing else abnormal was found. Four hours later she was bright mentally, but there was complete paralysis of the left arm, face and leg. The following morning there was no longer any paralysis, but she showed definite weakness of the left arm and leg. By September 21 the leg had fully recovered, but some hypotonia persisted in her arm. One week after admission, power had fully returned. On September 17 cerebro-spinal fluid examination for cells, protein, and organisms showed no abnormality. The fluid was not under pressure. On September 18 there appeared a transient widespread pink macular rash and the child was irritable. The rash recurred for short intervals during the two following days. The throat was normal. A temperature of $99^{\circ}-100^{\circ} \mathrm{F}$. with tachycardia had persisted from the time of admission. On September 23 pus cells and B. coli were abundant in a catheter specimen of urine. The pyelitis was treated with alkalies followed by mandelic acid, and the child quickly recovered.

Case 2, R. W., a thin pale boy four and a half years old, had had measles and whooping cough when aged three years. Eighteen months before admission he had a convulsion from which there was complete recovery in two hours. There were no sequelae. One and a half hours before admission on August 27,1938 , he went into convulsive coma, and remained stuporose until brought to hospital. Examination on admission showed continued stupor, with complete paralysis of the right face and arm and weakness of the right leg. The throat appeared normal. The temperature was $99^{\circ} \mathrm{F}$., pulse rate 128 and respirations 26 per minute. The paralysis was present three hours later, but not six hours later nor subsequently. Lumbar puncture was not done. The next day the temperature rose to $99.8^{\circ} \mathrm{F}$., the tonsils were enlarged and studded with follicles, and haemolytic streptococci were grown from the throat. The throat was treated and recovery followed. 


\section{Comment}

Transient paralyses are well known after the convulsions of idiopathic epilepsy. But it is worth considering that hemiplegia following symptomatic convulsions may be temporary, and not be of bad prognosis as regards the underlying disease. The convulsions in the above cases were not prolonged. This contrasts with the hemiplegia seen in apparently healthy children as a sequel to the sudden occurrence of a series of severe convulsions over a period of several days to a week (Pearson and Wyllie, 1935).

The conception of meningism might be usefully supplemented by that of ' encephalism,' a term which could be used to include symptomatic convulsions and their transient sequelae.

\section{Summary}

Two children are described, one with B. coli pyelitis and the other with acute tonsillitis, in whom the early symptoms were convulsions followed by temporary hemiplegias. Both children made good recoveries.

Thanks are due to Sir F. Menzies, Medical Officer of Health, London County Council, and Dr. D. S. Sandiland, Medical Superintendent, for permission to publish this report.

\section{REFERENCES}

Pearson, W. J., and Wyllie, W. G. (1935). Recent Advances in Diseases of Children, third edition, London, 205. 